\title{
Anna Camps \& Teresa Ribas (coords.), El verbo y su enseñanza. Hacia un modelo de enseñanza de la gramática basada en la actividad reflexiva, Barcelona, Octae- dro, 2017, 223 pp., ISBN 978-84-992I-895-3
}

Ens hem de congratular de la publicació d'aquest llibre, obra que representa i culmina un intens treball d'anys de GREAL (Grup de Recerca sobre Ensenyament i Aprenentatge de Llengües), dirigit per Anna Camps (UAB). El llibre destaca per la seua originalitat en diversos aspectes, com original i destacable és la manera com aquest grup ha treballat, en contacte directe entre investigadors i docents, en el que ells mateixos han denominat el "GREAL gran», una mena de seminari permanent on s'han posat en comú les recerques i les pràctiques d'aula.

El resultat de tan bona feina és aquest volum que gira al voltant d'una categoria gramatical, el verb, i l'aborda des dels reptes que planteja en l'ensenyament primari i secundari. Però aquest aspecte, el que ens indica el títol, pot considerar-se l' «excusa» per a una aportació que té un abast major: la presentació il.lustrada de manera polièdrica del model de seqüències didàctiques per a aprendre gramàtica (model SDG), presentat en Camps (2006). Aquest model proposa un ensenyament de la gramàtica basat en l'activitat reflexiva, com ens indica el subtítol de l'obra. El model SDG s'orienta a facilitar que «los alumnos diferencien formas [...], se pregunten por su uso y las utilicen conscientemente» (p. 95). I això implica fomentar una activitat de reflexió metalingüística dirigida a partir d'activitats de comprensió, anàlisi i producció, en un marc comunicatiu i reflexiu.

El llibre esdevé així una excel.lent mostra del model SDG i de com desenvolupar-lo i aplicar-lo a la investigació en didàctica de la llengua i, més important encara, a la tasca docent diària. De fet, la pràctica a l'aula és el punt de partida i d'arribada, amb el capítol inicial, programàtic, d'Anna Camps («Reflexiones sobre la enseñanza y el aprendizaje de la gramática») i el capítol final de Marta Milian i Teresa Ribas ("Características de un modelo de enseñanza de la gramática»), que es complementa amb una utilíssima bibliografia comentada, a càrrec de Carmen Durán i Xavier Fontich.

L'elecció del tema no és secundari. Parlar del verb és, de fet, parlar de tota l'oració i d'un element fonamental en la construcció discursiva: l'expressió de la temporalitat.

Però parlàvem al principi d'originalitat. Es tracta d'una obra coral, en què participen quinze autors i autores, la majoria del grup GREAL, que sorprèn pel caràcter unitari en el to i els objectius. Seria possible llegir l'obra com si fos d'un únic autor o autora i no hi trobaríem especials discordances o trets rellevants. Aquesta unitat queda representada pel fet que els capítols de l'índex no tenen el nom dels autors i autores, que apareixen en una pàgina prèvia de crèdits i encapçalant, això sí, cada capítol. Però 
aquesta unitat és encara més destacable si tenim en compte que entre els qui redacten els capítols hi ha autors consolidats en l'àmbit de l'estudi gramatical i de la didàctica de la llengua, però també autors relativament novells, persones que han preparat el capítol a partir de la seua tesi doctoral o d'experiències d'aula.

Aquest llibre plural explora una gran varietat d'aspectes i perspectives al voltant del verb i la reflexió sobre aquesta categoria gramatical per part de l'alumnat, en un tot harmònic on plantejament, experiències i conclusions particulars i generals s'integren perfectament. S’organitza en quatre blocs. El primer («Enseñar gramática: el verbo») inclou el capítol d'Anna Camps, ja esmentat, sobre els principis de l'ensenyament de la gramàtica i activitat metalingüística (observar la llengua i parlar sobre la llengua). Va seguit del capítol de Manuel Pérez Saldanya "La lingüística del verbo", on es tracten els principals conceptes que permeten analitzar aquesta categoria dins d'un marc més aviat oracional i de tall morfosintàctic, i el capítol de Felipe Zayas, "El verbo: diferentes perspectivas de la reflexión gramatical», que ens obre altres vies d'anàlisi que tenen en compte diferents plans, des del morfològic fins al discursiu: el verb com a classe de paraula, com a element organitzador de l'oració, com a element clau en la cohesió textual i, finalment, en el discurs, en relació amb la modalitat i els actes de parla, bàsicament. Potser un capítol és massa poc per a tots aquests aspectes (i potser alguns altres de caràcter més netament discursius i construccionals), que en la resta del llibre s'invoquen una vegada i una altra. $\mathrm{Si}$ «las formas del lenguaje no existen si no es en el discurso» (p. 26), és a dir, en ús, i «es necesaria una gramática que dé cuenta del uso de las formas en el discurso y de los significados que vehiculan; o sea, una gramática que integre los aspectos formales, semánticos y pragmáticos» (p. 3I), el bloc inicial hauria estat més complet si hagués dedicat més espai a les dimensions vinculades a l'ús del verb i la relació amb altres marques d'expressió de la temporalitat.

El segon bloc ens presenta els resultats d'investigacions amb alumnes de diferents nivells de primària i secundària relacionats amb diferents aspectes de l'ús del verb: els usos periferics del present (Mariona Casas), l'alternança subjuntiu/indicatiu a partir d'una tasca de contrast d'oracions a partir de parells mínims (Carmen Durán), els valors i usos dels temps verbals de passat (Carmen Rodríguez Gonzalo) i la classificació de verbs per a treballar la complementació (Xavier Fontich). Aquestes experiències no només ens ofereixen la descripció de la tasca i la recerca realitzades, sinó reflexions generals que van més enllà del punt analitzat $i$ del verb i poden orientar noves recerques i pràctiques de reflexió metalingüística i producció textual.

El tercer bloc planteja «¿Qué nos enseńa la experiencia del aula?». Inclou experiències realitzades per professores d'institut i docents universitaris que formen futurs mestres. María Rosa Gil, a partir de la frase típica d'infants «Mi gato se ha morido», 
analitza l'argumentació dels futurs mestres d'infantil sobre els errors gramaticals dels nens i nenes. Fina Martínez planteja la relació entre formes verbals i tipus de text en un aula de 6è de primària. Marta Giralt parla del treball del verb en microrelats sobre pirates. M. Teresa Verdaguer i Oriol Guasch analitzen l'ús dels verbs en narracions des d'una perspectiva contrastiva (català-anglès) com a base per a l'activitat reflexiva. Finalment, Rosalía Delgado explora el canvi de discurs directe a indirecte amb alumnes amb dificultats acadèmiques de $3 \mathrm{r}$ ESO.

El quart bloc («Recapitulemos pensando en la práctica»), com hem avançat a l'inici de la ressenya, recapitula el model subjacent i presenta propostes per a un model d'ensenyament de la gramàtica basat en la reflexió i en la interacció, i ofereix consells bibliogràfics respecte a la interacció d'aula al voltant del verb, l'ensenyament de la gramàtica, els estudis de lingüística més útils per a aquest treball i es completa amb propostes en línia.

El llibre és ric en reflexions i propostes. En destacaré només algunes, que m’han interessat especialment.

La proposta del grup GREAL toca una qüestió controvertida, en la mesura que reclama el treball didàctic de la gramàtica explícita. És aquest aspecte en el qual s'ha observat un moviment pendular important: si fa dècades la defensa de la gramàtica explícita i la reflexió metalingüística era innecessària perquè ningú no la qüestionava, posteriorment (i encara ara) es qüestiona com a activitat innecessària o fins i tot contraproduent. El famós mètode gramàtica-traducció amb què estudiàvem el llatí és una bona mostra d'aquesta tendència. La reacció a aquests mètodes, sobretot amb l'adveniment de l'enfocament comunicatiu des de final dels setanta, va obrir la porta a un ensenyament de la llengua que deixa en segon lloc la gramàtica i pressuposa que amb una construcció implícita de conceptes n’hi ha prou. El grup GREAL se situa en un punt intermedi: la reflexió gramatical ha de tenir un lloc però no s'ha de vehicular unidireccionalment, del professor, com a expert, a l'alumne, com a participant receptiu o reactiu, sinó en un marc de reflexió interactiva, com una activitat més de la classe de llengua en què anem «del uso de la lengua a los conceptos abstractos y a su sistematización, y de este conocimiento sistemático a un mayor dominio de la lengua a través del uso reflexivo y consciente» (p. 29).

Aquest procés passa, òbviament, per una redefinició del paper de docent i aprenent, el primer com a acompanyant i guia més que transmissor de coneixements i jutge, i el segon com a participant actiu en un clima d'indagació a partir de la interacció.

La lectura de l'obra suscita també la vella qüestió de la relació entre lingüística i ensenyament de llengües, una relació difícil, d'amor-odi, en què hi ha necessitat i asimetria: l'ensenyament de la llengua, i més encara la reflexió gramatical, necessita 
una teoria lingüística, un model (existent o construït amb les aportacions de diferents models preexistents), que es basa en alguns axiomes o pressupòsits que condicionen la visió de la llengua i l'adequació a l'aplicació a l'aula. Els models tradicionals, i d'altres de més moderns com l'estructuralista o el generativista (vegeu Cuenca 1992), presenten problemes importants. Els capítols del llibre reclamen, de manera més o menys explícita, un bastiment teòric basat en l'ús, comunicatiu, multidimensional i que tinga en compte el caràcter dinàmic i difús de les categories lingüístiques. Aquest enfocament està en la línia d'una gramàtica funcional com la de Halliday (vg. Halliday \& Matthiessen 2004) o, més en general, de diferents enfocaments que participen dels principis de la lingüística cognitiva (vg. Cuenca \& Hilferty 1999; Ibarretxe \& Valenzuela 20I2), a més de les contribucions a la gramàtica del text o l'anàlisi del discurs. Cal, doncs, una redefinició de la gramàtica per tal que puga ser pedagògica. Hi ha una «necesidad de reestructurar o reconfigurar [...] los contenidos gramaticales para acercarlos a los usos discursivos» (p. I88).

Però els models s'han de desenvolupar i preparar per a ser aplicables. En aquest punt, esdevé fonamental la formació lingüística dels futurs ensenyants, que no sembla ser suficientment sòlida ni adequada. Els docents han de tenir un coneixement complet del funcionament de la gramàtica, com a usuaris i en el nivell metalingüístic. Laportació de M. Rosa Gil mostra que no és així. Aquest és un punt que cal atacar. És central que hi haja en els currículums assignatures de formació lingüística basades en la interrelació entre gramàtica i ús.

En conjunt, tenim davant una obra amb múltiples reflexions teòriques i propostes d'aula ben elaborades i basades en un model coherent comú. Animem coordinadores, autores i autors a continuar aquesta línia de treball que contribueix a emplenar un buit en l'ensenyament de la gramàtica. Potser no gaire tard podrem trobar un volum semblant, per exemple sobre l'oració, concepte bàsic i alhora controvertit i misteriós per a més d'una persona, docent o estudiant?

\author{
Maria Josep Cuenca \\ Universitat de València \\ Institut d'Estudis Catalans \\ maria.j.cuenca@uv.es
}




\section{REFERÈNCIES BIBLIOGRÀFIQUES}

CAmps, A. (2006) «Secuencias didácticas para aprender gramática (SDG)», dins A. Camps \& F. Zayas (coords.), Secuencias didácticas para aprender gramática, Barcelona, Graó, pp. 3I-48.

Cuenca, M. J. (1992) Teories gramaticals i ensenyament de llengües, València, Tàndem. Cuenca, M. J. \& J. Hilferty (1999) Introducción a la lingüistica cognitiva, Barcelona, Ariel.

IbarretXe-Antuñano, Iraide \& Javier Valenzuela, eds. (2OI2) Lingüistica cognitiva, Barcelona, Anthropos.

Halliday, M. A. K. \& Ch. Matthiessen (2004) An Introduction to Functional Grammar, za edició, Londres, Arnold. 